\title{
Differentiated selection method to admission in medical education
}

\section{Raushan Dosmagambetova ${ }^{1}$, Gulshat Kemelova ${ }^{2}$, Aida Kassatova ${ }^{3}$, Victor Riklefs ${ }^{4}$}

${ }^{1}$ Rector, Karaganda State Medical University, Karaganda, Republic of Kazakhstan

${ }^{2}$ Practical Skills Centre, Karaganda State Medical University, Karaganda, Republic of Kazakhstan

${ }^{3}$ Department of Academic Work, Karaganda State Medical University, Karaganda, Republic of Kazakhstan ${ }^{4}$ Vice-rector for Education, Karaganda State Medical University, Karaganda, Republic of Kazakhstan International License

Received: 2018-03-27

Accepted: 2018-06-05

UDC: 616.1

\section{J Clin Med Kaz 2018;2(48):41-46}

Corresponding Author: Gulshat Kemelova, MD, Ph.D., Practical Skills Centre, Karaganda State Medical University. Address: 40, Gogol street, Karaganda city, Kazakhstan. Tel.:+77015908826, Fax: +77212503930 E-mail: kemelova@kgmu.kz

\section{Abstract}

The aim: To compare the results of multiple mini-interviews with the results of medical students' achievements after the completion level of study.

Methods: The study was conducted to determine the efficacy, validity, and reliability of the multiple mini-interview methods for differential selection and admission to medical education organizations. The study assessed the ability to learn with the definition of the professional suitability of students of 1 year of study $(n=491)$ with the help of multiple mini-interviews, followed by their academic achievements for two years, evaluated the final results for the Grade Point Average after each stage of the study.

Results: Analysis of the results showed that the multiple mini-interviews are a suitable method to evaluate candidates' ability to study in medicine, which assesses a creative thinking, communication skills, and a personal behavior. Candidates with high scores of the United National Testing and multiple mini-interviews confirm their abilities with academic achievements, however, they account for a one-third of the total. $12 \%$ of students, who have left the university at their own will, had average United National Testing results and low multiple mini-interviews scores, which indicated their low motivation to study in medicine and lack of willingness to overcome learning difficulties. Annually more than $15 \%$ of students re-study some of the disciplines, and this is also due to the fact that they do not study with the curriculum. The high results of multiple mini-interviews matched with the high results of United National Testing and educational achievements in only $23.6 \%$ of the total number of candidates, which show the reliability and applicability of the method studied.

Conclusion: Multiple mini-interview is the most suitable method for qualitative differentiated selection and admission of applicants to medical universities, which allows to evaluate and predict professional suitability and to minimize the number of "casual" students in medicine. Multiple mini-interview is a reliable and acceptable method and is recommended to be introduced as an additional exam for admission to medical universities.

Keywords: multiple mini-interview, student, differentiate selection

\footnotetext{
МЕДИЦИНАЛЫҚ БІЛІМ БЕРУ ҰЙЫМДАРЫНДА ОҚЫТУҒА АРНАЛҒАН САРАЛАП ТАНДАУДЫН ӘДІСІ

Досмагамбетова Р.С. ${ }^{1}$, Кемелова Г.С. ${ }^{2}$, Касатова А.М. ${ }^{3}$, Риклефс В.П. ${ }^{4}$

${ }^{1}$ Ректор, Қарағанды мемлекеттік медицина университеті, Қарағанды, Қазақстан Республикась

${ }^{2}$ Практикалық дағдылар орталығы, Қарағанды мемлекеттік медицина университеті, Қарағанды, Қазақстан Республикасы

${ }^{3}$ Академиялық жұмысы бойынша департаменті, Қарағанды мемлекеттік медицина университеті, Қарағанды, Қазақстан Республикасы

${ }^{4}$ Оку-әдістемелік бойынша проректор, Қарағанды мемлекеттік медицина университеті, Қарағанды, Қазақстан Республикасы
}

\section{ТҰЖЫРЫМДАМА}

Зерттеу мақсаты: Медициналық жоғары оқу орындары студенттерінің оқу кезеңі аяқталғаннан кейінгі жеткен нәтижелерімен жиынтық шағын-сұхбат нәтижелерін, яғни оның тиімділігін бағалау үшін салыстыру.

Әдістері: Медициналық білім беру ұйымдарына сараланған іріктеу және қабылдау үшін жиынтық шағын-сұхбат әдісінің сенімділігін және тиімділігін анықтау бойынша проспективті когортты зерттеу жүргізілді. Зерттеу кезінде жиынтық шағын-сұхбат көмегімен 1 жыл оқыған студенттердің (n=491) кәсіби жарамдылығын анықтай отырып, оқытуға қабілетін бағалады, сонымен қатар екі жыл бойы олардың оқу саласында жеткен жетістіктерін бақылап, оқытудың әрбір кезеңі аяқталғаннан кейін Grade Point Average бойынша соңғы нәтижелерін бағалады.

Нәтижесі: Зерттеу нәтижесі жиынтық шағын-сұхбат көмегімен кандидаттардың бойынан медицина саласында оқуға қабілетін, шығармашылық ойлауын, коммуникативті дағдыларын және тұлғалық сапасын бағалауға болатынын көрсетті. Ұлттық Біріңғай Тестілеу және 
жиынтық шағын-сұхбат жоғары балын иемденген кандидаттар өздерінің академиялық жетістікке жету қабілеттерін дәлелдейді, алайда олар жалпы көрсеткіштің үштен бірін ғана құрайды. Өз еріктерімен оқудан шыққан білім алушылардың (12\%) Ұлттық Біріңғай Тестілеу көрсеткен орташа нәтижесі мен жиынтық шағын-сұхбат бойынша төменгі балы олардың медицина саласында оқуға деген мотивациясының төмен екендігін айғақтайды. Жыл сайын студенттердің 15\% пәндерді қайталап оқуға бағытталып отырады, бұл олардың оқу бағдарламасын меңгеруге шамасының келмейтініне байланысты. Жиынтық шағын-сұхбат жоғары балы Ұлттық Біріңғай Тестілеу жоғарғы нәтижелерімен сәйкес келеді және жалпы кандидаттардың ішінде тек 23,6\% ғана оқуда жетістікке жетуде, ал бұл дегеніңіз зерттеліп жатқан әдістің сенімділігін көрсетеді.

Қорытынды: Жиынтық шағын-сұхбат - медициналық жоғары оқу орындарына талапкерлерді саралап таңдау мен қабылдаудың аса тиімді әдістерінің бірі болып табылады және кәсіби жарамдылықты болжауға, бағалауға мүмкіндік беріп, медицинадағы «кездейсоқ» студенттердің санын азайтуға әкеледі. Жиынтық шағын-сұхбат әдісі сенімді болып табылады және оны медициналық білім беру ұйымдарына түсуге арналған қосымша емтихан ретінде енгізуге ұсынылады.

Негізгі сөздер: жиынтық шағын сұхбат, студент, саралап таңдау

\section{СПОСОБ ДИФФЕРЕНЦИРОВАННОГО ОТБОРА ДЛЯ ОБУЧЕНИЯ В МЕДИЦИНСКИХ ОРГАНИЗАЦИЯХ ОБРАЗОВАНИЯ}

Досмагамбетова Р.С. ${ }^{1}$, Кемелова Г.С. ${ }^{2}$, Касатова А.М. ${ }^{3}$, Риклефс В.П..

'Ректор, Карагандинский государственный медицинский университет, Караганда, Казахстан

²Центр практических навыков, Карагандинский государственный медицинский университет, Караганда, Республика Казахстан

${ }^{3}$ Департамент по академической работе, Карагандинский государственный медицинский университет Караганда, Република Казахстан

${ }^{4}$ Проректор по учебно-методической работе, Карагандинский государственный медицинский университет Караганда, Республика Казахстан

\section{РЕЗЮМЕ}

Цель исследования: Сравнить результаты множественного мини-интервью с результатами достижений студентов медицинского вуза после завершения этапа обучения для оценки его эффективности.

Методы: Было проведено проспективное когортное исследование по определению эффективности и надежности множественного мини-интервью как метода для дифференцированного отбора и приема в медицинские организации образования. В исследовании с помощью множественного мини-интервью оценивали способности к обучению с определением профессиональной пригодности студентов 1 года обучения ( $n=491)$, наблюдали за их учебными достижениями в течение двух лет, оценивали конечные результаты по Grade Роint Аverage после завершения каждого этапа обучения.

Результаты: Анализ результатов исследования показал, что с помощью множественного мини-интервью можно оценить у кандидатов способность к обучению в медицине, творческое мышление, коммуникативные навыки и личностные качества. Кандидаты с высокими баллами ЕНТ и ММИ подтверждают свои способности академическими достижениями, однако их доля составляет одну треть от общего числа. Обучающиеся, отчисленные по собственному желанию (12\%) имели средние результаты ЕНТ и низкие баллы по ММИ, что свидетельствует об их низкой мотивации к обучению в медицине и не готовности преодолевать трудности в обучении. Ежегодно более 15\% студентов направляются на повторное изучение дисциплины, и это также связано с тем, что они не справляются с учебной программой. Высокие результаты ММИ совпадают с высокими результатами ЕНТ и учебными достижениями только у $23,6 \%$ от общего числа кандидатов, что показывает надежность и применимость исследуемого метода.

Заключение: Множественное мини-интервью является наиболее подходящим методом для качественного дифференцированного отбора и приема абитуриентов в медицинские вузы, который позволяет оценить и прогнозировать профессиональную пригодность, и минимизировать количество «случайных» студентов в медицине. Множественное мини-интервью является надежным и приемлемым методом и рекомендуется внедрить как дополнительный экзамен для поступления в медицинские организации образования.

Ключевые слова: множественное мини-интервью, студент, дифференцированный отбор

\section{Введение}

Формирование специалиста здравоохранения является главной и важной задачей медицинских организаций образования, однако это труднодостижимая задача, которую не в силах решать отдельные медицинские вузы. Анализ текущей ситуации поступления в медицинские организации образования показывает, что в медицинские университеты поступают те, кто прошел общую процедуру отбора по результатам Единого Национального тестирования (ЕНТ), и другого способа отбора в медицинские вузы на сегодняшний деньнет [1].Всвязисвозрастающимитребованиямиобщества и государства медицинские организации образования должны готовить специалистов здравоохранения коммуникабельных, мобильных, с развитым логическим мышлением, способных легко и быстро адаптироваться к меняющимся жизненным ситуациям, постоянно работающих над саморазвитием и самосовершенствованием [2]. Проводимый общегосударственный конкурс на основе ЕНТ не позволяет проводить тщательный отбор абитуриентов, и оценить мотивацию абитуриентов к изучению медицинских специальностей. В связи с этим, можно выделить ряд причин, которые могут прояснить данную проблему: школьники мало информированы о будущей профессии; профессиональная ориентация не дает требуемого эффекта, поэтому обучающиеся первого года обучения неспособны преодолевать трудности обучения в медицинском вузе; и большинство студентов не осознают важность и ответственность будущей профессии. Практика приема и отбора абитуриентов на основе результатов ЕНТ показала, что 10-12\% первокурсников «отсеиваются» по собственному желанию, недоучившись до конца первого семестра [3], при этом частой причиной отчисления является «неспособность адаптироваться к новым условиям» и «неверный выбор будущей профессии» [4]. Критериями, определяющими профессиональную пригодность к обучению, являются общая подготовленность к обучению, особенности характера, уровень интеллектуального развития [5]. Профессиональная пригодность является залогом успешного овладения профессией, благоприятной адаптации к обучению и условиям труда, которая способствует также эффективной профессиональной деятельности на протяжении всей жизни [6]. В международной практике более 20 лет используются различные дополнительные критерии отбора в медицинские вузы, такие как психометрическое тестирование, множественное миниинтервью (ММИ), простое интервью, портфолио и др. С целью изучения методов дифференцированного отбора и оценки эффективности, валидности и надежности нами был изучен метод множественного мини-интервью. Метод ММИ вызвал интерес тем, что можно оценить абитуриента сразу по нескольким критериям: способность к обучению, интеллектуально-творческая активность, умение критически мыслить, личностные качества. Принцип проведения ММИ очень похож на объективный структурированный клинический экзамен (ОСКЭ) и, учитывая то, что в вузе имеется 7-летний опыт проведения данного формата 
экзамена, технология проведения ММИ была ясной и понятной всем участникам проекта, за исключением кандидатов. Были определены задания на каждую станцию, определены обязанности и функции всех участников ММИ (группа сопровождения, интервьюеры, кандидаты и приемная комиссия), а также критерии оценивания результатов интервью. Данный метод нами был тестирован на студентах, зачисленных в вуз по общегосударственным типовым правилам.

Целью исследования явилось сравнение результатов множественного мини-интервью с результатами достижений студентов медицинского вуза после завершения этапа обучения для оценки его эффективности.

\section{Методы}

В 2014-2015 учебном году в Карагандинском Государственном Медицинском университете было проведено пилотирование множественного мини-интервью среди студентов 1 курса специальности «общая медицина». Для организации ММИ был составлен план-график, включающий подготовку интервьюеров, определения количества станций на ММИ, задания на каждую станцию, определены группа сопровождения, состав приемной комиссии, группы студентов, разработаны материалы для проведения инструктажа всех участников. Объектом исследования явились студенты специальности «общая медицина» $(\mathrm{n}=491)$.В данномисследованиивсеобучающиеся, участвовавшие в ММИ были определены как «кандидаты». Дизайн исследования - описательное проспективное когортное исследование. В исследовании были определены критерии включения - студенты 1 курса специальности «общая медицина». Критерии исключения - студенты старше 1 курса других специальностей. Для сравнения результатов ММИ были анализированы также баллы GPA по окончании каждого года обучения с использованием дополнительных характеристик из деканата. Для решения задач исследования была проведена подготовительная работа: подготовка интервьюеров и членов комиссии, подготовка студентов по прохождению ММИ, отлажена логистика между участниками множественного мини-интервью. Для подготовки «кандидатов» к прохождению процедуры ММИ был проведен специальный инструктаж для студентов. В качестве примера для понимания цели проведения ММИ с кандидатами были обсуждены несколько ситуационных сценариев, обсуждены пошаговые действия кандидата до начала ММИ и во время непосредственного проведения интервью, а также взаимодействие с интервьюером и другими членами группы сопровождения ММИ. Результаты исследования обрабатывались статистическим методом с использованием индекса дискриминации, коэффициента корреляции и альфа Кронбаха.

\section{Результаты}

В данном исследовании участвовали 491 студент специальности «общая медицина», из них 264 (54\%) студента обучаются на казахском языке обучения, 227 (46\%) студентов обучаются на русском языке обучения. Для сравнения эффективности множественного миниинтервью были анализированы учебные достижения студентов по уровню среднего балла успеваемости - Grade Point Average (GPA) - это средневзвешенная оценка уровня учебных достижений обучающегося за один учебный год по выбранной образовательной программе. В рамках исследования были использованы результаты GPA после первого года обучения (GPA1) и после второго года обучения (GPA2). Все обучающиеся, участвовавшие в ММИ, по «входным» результатам ЕНТ были разделены на 3 группы: 1 группа - кандидаты с результатами ЕНТ от 90 до 100 баллов, 2 группа - с результатами ЕНТ от 75 до 89 баллов и 3 группа - с результатами ЕНТ 74 балла и ниже. Максимальный результат ЕНТ по всему курсу составлял 100 баллов. С целью изучения количества выбывших из общего числа кандидатов, были изучены причины отчисления студентов после 1 и 2 года обучения (Таблица 1).

Таблища 1 Коэффициенты корреляционного анализа между квантилями ФПР и ФР ССО и другими клиникоІаблица 1 лабораторными показателями

\begin{tabular}{|c|c|c|c|c|c|c|c|c|c|c|}
\hline \multirow[t]{2}{*}{ Группы } & \multicolumn{2}{|c|}{ Перевод в другой вУЗ } & \multicolumn{2}{|c|}{ Академический отпуск } & \multicolumn{2}{|c|}{$\begin{array}{l}\text { Отчисление по соб- } \\
\text { ственному желанию }\end{array}$} & \multicolumn{2}{|c|}{ Нарушение ПТВР** } & \multicolumn{2}{|c|}{ Всего } \\
\hline & $\mathrm{K}^{*}$ & $\mathrm{P}^{*}$ & К & $P$ & K & $P$ & К & $P$ & K & $P$ \\
\hline 1 & 16 & 12 & 1 & 1 & 3 & - & 1 & - & 21 & 13 \\
\hline 2 & 1 & 7 & 1 & - & 1 & 6 & - & - & 3 & 13 \\
\hline 3 & - & 1 & - & - & - & - & - & - & - & 1 \\
\hline Всего & 17 & 20 & 2 & 1 & 4 & 6 & 1 & - & 24 & 27 \\
\hline \multicolumn{11}{|c|}{51 (10,4\% от общего числа, прошедших ММИ, и обучавшихся на 1 курсе) } \\
\hline 1 & 1 & 1 & - & & - & 3 & 3 & - & - & \\
\hline 2 & - & - & - & - & & - & - & - & - & \\
\hline 3 & - & & - & - & - & & & & & \\
\hline Всего & 1 & 1 & 5 & 4 & 6 & 5 & & & & \\
\hline
\end{tabular}

Примечание:

К* - казахский язык обучения, $\mathrm{P}^{*}$ - русский язык обучения

ПТВР** - Правила трудового (внутреннего) распорядка

За двухлетний период обучения, из числа пройденных ММИ, было отчислено $12 \%$. К концу 1 года обучения осталось 440 студентов, из них на казахском языке обучения 240 (54,5\%) участников, на русском языке обучения 200 $(45,5 \%)$ участников. В течение первого года обучения 51 обучающихся были отчислены из вуза, что составило 10,4\% от общего числа «кандидатов», из них 53\% составили студенты из групп русского языка обучения, 47\% - из групп казахского языка обучения. От общего числа 51 отчисленных студентов 72,5\% перевелись в другие вузы, и 19,6\% покинули вуз с формулировкой «отчисление по собственному желанию». Следует отметить, что студенты, 
переведенные в другой вуз, не являются коренными жителями тех городов, куда был сделан выбор перевода из вуза в вуз. Все студенты, переведенные в другой вуз, это кандидаты, не набравшие проходной балл GPA на последующий курс, и это свидетельствует о том, что они не справились с учебной программой. По завершению 2 года обучения из числа участников ММИ были отчислены ещё 11 обучающихся, из них 2 студента «с переводом в другой вуз», остальные были отчислены «по собственному желанию». Так, за два года обучения были отчислены 62 обучающихся, что составило $12 \%$ от общего числа, участвовавших в ММИ, из них $85,5 \%$ обучались на образовательном гранте и 14,5\% на платной основе, т.е. не выгодно обучать случайно поступивших студентов, так как экономические затраты не были оправданы. И, тем не менее, студенты, имеющие государственный образовательный грант, имеют больше свободы по переводу в другие вузы, по сравнению со студентами, обучающимися на платной основе. Так, дифференцированный отбор абитуриентов на «входе» будет способствовать минимизации финансовых и профессиональных рисков.

В Таблице 2 представлены результаты сравнительных данных по баллам ЕНТ, ММИ, языкам обучения и результатам GPA1, GPA2. По результатам баллов ЕНТ структура групп представлена следующим образом: 1 группу составили 290 $(65,9 \%)$ кандидатов, имеющие очень высокие баллы ЕНТ, 2 группу составили 135 (30,7\%) кандидатов со средними баллами ЕНТ и 3 группу составили 15 (3,4\%) кандидатов с низкими баллами ЕНТ.

Таблица 2 Структура по баллам ЕНТ, результатам ММИ, языкам обучения и результатам GPA1, GPA2.

\begin{tabular}{|l|l|l|l|l|l|l|l|l|l|l|}
\hline Группа & $\begin{array}{l}\text { Баллы } \\
\text { ЕНТ }\end{array}$ & $\begin{array}{l}\text { Казахский } \\
\text { язык }\end{array}$ & ММИ, \% & GPA 1 & GPA 2 & $\begin{array}{l}\text { Русский } \\
\text { язык }\end{array}$ & $\begin{array}{l}\text { ММИ, } \\
\text { \% }\end{array}$ & GPA1 & GPA 2 & Всего \\
\hline 1 & $90-100$ & $\begin{array}{l}205 \\
(70,7 \%)\end{array}$ & 68,3 & 3,34 & 2,94 & $85(29,3 \%)$ & 68,1 & 3,35 & 3,00 & $\begin{array}{l}290 \\
(65,9 \%)\end{array}$ \\
\hline 2 & $75-89$ & $30(22,3 \%)$ & 65,4 & 3,03 & 3,02 & $\begin{array}{l}105 \\
(77,7 \%)\end{array}$ & 64,2 & 3,04 & 3,01 & $\begin{array}{l}135 \\
(30,7 \%)\end{array}$ \\
\hline 3 & $<74$ & $5(33,3 \%)$ & 69,1 & 2,69 & 2,32 & $10(66,7 \%)$ & 74,4 & 3,02 & 2,31 & $15(3,4 \%)$ \\
\hline & Итого & $\begin{array}{l}240 \\
(54,5 \%)\end{array}$ & 67,6 & 3,02 & 2,76 & $\begin{array}{l}200 \\
(45,5 \%)\end{array}$ & 68,9 & 3,13 & 2,77 & $\begin{array}{l}440 \\
(100 \%)\end{array}$ \\
\hline
\end{tabular}

Как видно из Рисунка 1, 1 группу составили 70,7\% кандидатов, обучающиеся на казахском языке и 29,3\% кандидаты, обучающиеся на русском языке. Во 2 группе кандидатов из русского отделения оказалось больше, чем из казахского отделения, $77,7 \%$ и $22,3 \%$ соответственно, также в 3 группе кандидатов из русского отделения составило в 2 раза больше, чем кандидатов из казахского отделения, а именно $66,7 \%$ и $33,3 \%$ соответственно.

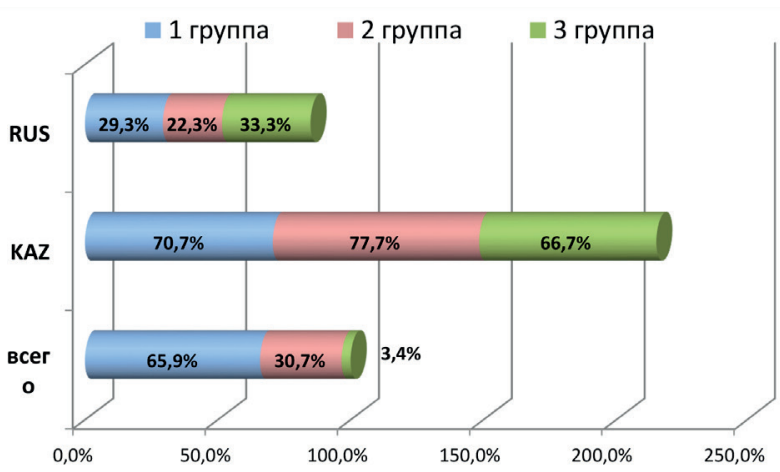

Рисунок 1 - Структура групп по результатам ЕНТ и языкам обучения

На рисунке 1 представлены данные по распределению баллов и их соответствие с пороговым баллом. В данном случае альфа Кронбаха составляет 0,711, средняя стандартная ошибка 3,95 SEm\%, в стандартное отклонение 7,35\%. Количество участников, набравших баллы ниже порогового уровня, составило 183 (41,5\%). Коэффициент корреляции баллов с баллом ММИ $\mathrm{r}=0,852$. В целом, средний балл по ММИ составил $67,4 \%$, этот экзамен для студентов оказался наиболее сложным. Средний индекс дискриминации составил 0,15 , средняя корреляция с итоговым баллом 0,58 .
Сравнение результатов ММИ и ЕНТ показало, что у более половины кандидатов 1 группы имеются способности к обучению ниже, чем у кандидатов 3 группы, однако, уровень GPA1 показывает, что кандидаты 1 группы имеют достаточно хорошие учебные достижения. После окончания второго года обучения кандидаты 1 группы продемонстрировали «средние» результаты GPA2, что свидетельствует о снижении способности к обучению, особенно в казахских группах обучения $(\mathrm{GPA} 2=2,94)$. При этом следует отметить, что результаты GPA2 были взяты в учет после повторного прохождения дисциплины, то есть после повышения GPA. Так, среди кандидатов 1 группы на повторное изучение дисциплин было отправлено 14 $(2,7 \%)$ человек, со 2 группы - 8 (5,9\%) человек и с 3 группы - 1(6,6\%) человек. По учебным достижениям средний балл результатов GPA по окончании 1 и 2 годов обучения на казахском языке обучения составил GPA 1 - 3,02 и GPA2 2,76 соответственно, на русском языке обучения GPA1 - 3,13 и GPA2 - 2,77 соответственно. В 1 группе только у одного кандидата результат ММИ был 90 баллов, что составило $0,3 \%, 24 \%$ кандидатов набрали от 75 до 87 баллов, $72 \%$ кандидатов набрали от 50 до 74 баллов, и 3,8\% кандидатов набрали ниже 49 баллов. Среди студентов с очень низким баллом ММИ были те, чьи баллы ЕНТ были в пределах от 95 до 100 (63,3\%). В этой группе у 2 студентов после 1 года обучения GPA был ниже порогового уровня, после второго года обучения число не набравших пороговый уровень GPA увеличилось до 57 (19,6\%). Так, данная группа кандидатов была направлена на повторное изучение дисциплин с целью повышения уровня GPA.

Во 2 группе у одного студента результат ММИ был 92 балла, что составил $0,7 \%$ от общего числа кандидатов, $20,7 \%$ кандидатов набрали от 75 до 83 баллов, 71\% кандидатов набрали от 50 до 74 баллов, 7\% кандидатов набрали ниже 49 баллов. Среди кандидатов с очень низким баллом ММИ были обучающиеся с баллом ЕНТ выше 81 балл. В этой 
когорте только у двоих студентов не был набран пороговый уровень GPA после первого года обучения (13\%), а после 2 года обучения у $25 \%$ обучающихся.

В 3 группе кандидаты с низким баллом ЕНТ также имели низкий балл ММИ, однако, имеются кандидаты с низким баллом ЕНТ, но получившие высокие баллы ММИ. У $73 \%$ кандидатов из данной когорты GPA был выше 3,0 после первого года обучения, и, тем не менее, после завершения 2 года обучения у 66,6\% студентов не был набран проходной балл GPA. Студенты, не набравшие проходной бал GPA, были направлены на повторное изучение дисциплин в летнем семестре.

На Рисунке 2 ниже представлены данные по распределению баллов ММИ и их соответствие с пороговым баллом. Коэффициент альфа Кронбаха показывает внутреннюю согласованность данных, описывающих объект, показывая надежность экзамена. В случае альфа Кронбаха выше 0,7 интерпретируется как «достаточно надежный» метод. В данном исследовании альфа Кронбаха составил 0,711, что свидетельствует о надежности и валидности ММИ. Средняя стандартная ошибка оценки регрессии составила 3,95 SEm\% и интерпретируется как нормальное стандартное отклонение выборки из всей генеральной совокупности, при этом стандартное отклонение составило 7,35\%. Анализ данных показал, что 183 (41,5\%) кандидата набрали баллы ММИ ниже порогового уровня, что могло расцениваться, как не прошедшие пороговый уровень ММИ и не могли быть приняты в ВУЗ.

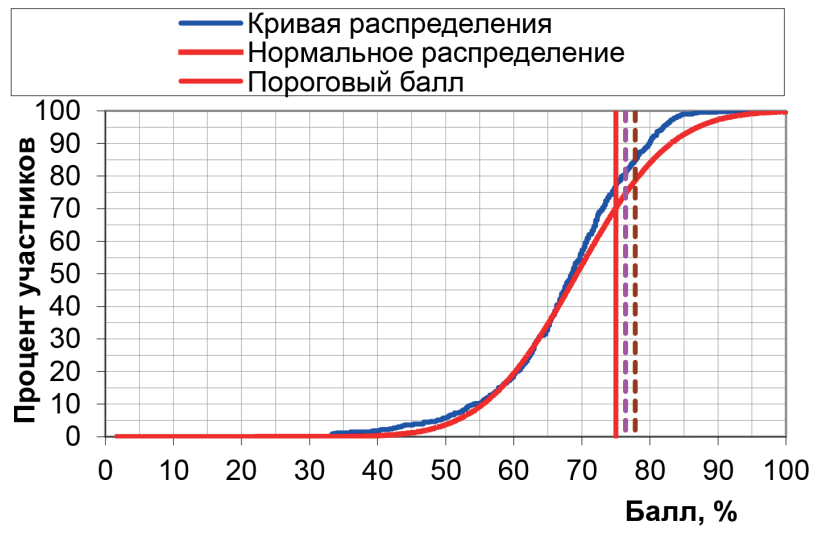

Рисунок 2 - Распределение баллов и их соответствие пороговым баллам

При рассмотрении критериев оценочного листа по отдельным категориям получается, что 140 (28,5\%) обучающихся продемонстрировали смогли способность к обучению, творческая активность 96 (19,5\%), критичность мышления 98 (20,0\%), личностные качества 180 (36,6\%) от общего числа участвовавших в ММИ. Однако, при принятии $75 \%$ баллов как пороговый уровень, только 116 студентов набирают этот «порог», что составило $23,6 \%$, остальные «условно не могли бы быть приняты в ВУЗ».

Коэффициент корреляции баллов ЕНТ с баллом ММИ составил $\mathrm{r}=+0,852$, это показывает силу связи между переменными как «высокая» и свидетельствует о взаимосвязи данных ЕНТ и ММИ. В целом, средний балл по ММИ составил 67,4\%, и этот экзамен для студентов оказался наиболее сложным. Средний индекс дискриминации составил 0,15 , так как данный статистический параметр находится между 0 и +1 , то можно интерпретировать следующим образом: все кандидаты, имеющие высокие результаты ЕНТ ответили правильно на ММИ, слабые отвечали соответственно слабо, а это в свою очередь подтверждает точность тестирования кандидатов по ММИ. При этом средняя корреляция с итоговым баллом составила 0,58, и это свидетельствует о достаточной надежности формата ММИ.

Как видно из Рисунка 3, критерии оценочного листа по ММИ были рассмотрены по 4 основным критериям: способность к обучению, творческая активность, критичность мышления и личностные качества.

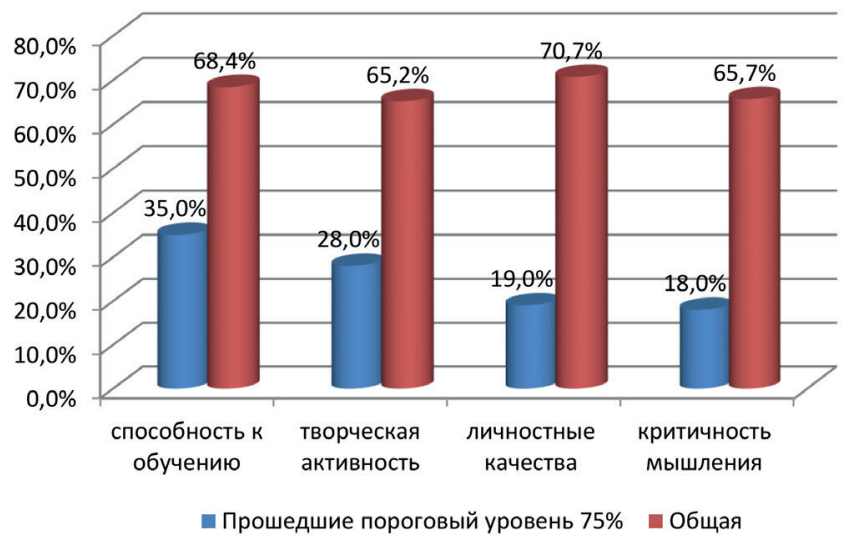

Рисунок 3 - Распределение по категориям оценочного листа ММИ

Каждая категория оценочного листа включала по 4 критерия с целью детализации данных параметров, и оценивалась по шкале от 0 до 10. Обобщенные данные по 4 категориям оценочного листа показали, что 140 (28,5\%) обучающихся продемонстрировали хорошие способности к обучению, 96 (19,5\%) - творческую активность, 98 (20,0\%) - критичность мышления, 180 (36,6\%) - личностные качества от общего числа, участвовавших в ММИ. Так, 116 кандидатов с высоким проходным баллом ММИ и продемонстрировавшие очень хорошие способности к обучению по 4 параметрам оценочного листа, завершили 2 года обучения с высокими баллами GPA без академических задолженностей на протяжении 2 лет обучения. В случае установления 75\% баллов как пороговый проходной уровень ММИ, только 116 студентов смогли бы набрать этот «порог», что составляет $23,6 \%$ от общего числа кандидатов, остальные условно «не могли бы быть приняты в вуз». Студенты с низкими результатами ММИ не могли быть исключены из числа студентов, т.к. данная процедура отбора не является официально признанной процедурой.

Таким образом, множественное мини-интервью является достаточно хорошим и подходящим методом дифференцированного отбора для отбора и приема в медицинские организации образования. Кандидаты, имеющие высокий балл ММИ подтверждают на мини-интервью, а также по результатам ММИ можно прогнозировать профессиональную пригодность в медицине будущих специалистов здравоохранения. Свободная обстановка при проведении ММИ позволяет «раскрыться» кандидату, свободно выражая свои мысли и убеждения, а также данный формат интервью для оценки профессиональной пригодности не требует много ресурсов. 


\section{Обсуждение}

Имея цель оценить эффективность множественного мини-интервью как метода для дифференцированного отбора и приема кандидатов в медицинские вузы, было проведено проспективное когортное исследование. Для реализации задач исследования была проведена тщательная подготовка по проведению данного метода мини-интервью. Множественное мини-интервью было протестировано среди студентов 1 курса специальности «общая медицина». Проведенный нами сравнительный анализ эффективности ММИ и результатов ЕНТ показал, что кандидаты с высокими результатами ЕНТ и с высокими результатами ММИ имеют очень хорошие способности к обучению медицине и можно прогнозировать, что из них получатся очень хорошие специалисты здравоохранения, а это составляет одну треть от общего сила кандидатов. Результаты исследования по определению эффективности ММИ показали, что итоговая оценка, полученная на ММИ, совпадает с оценками, полученными на протяжении обучения в медицинском университете. ММИ позволяет отбирать претендентов не только по академическим способностям, но и по коммуникативным и межличностным навыкам. Кроме этого, использованные в ММИ задачи, подтвердили валидность и надежность данного метода.

Отмечен интересный факт, что кандидатов с высоким баллом ЕНТ составили 290 (65,9\%) обучающихся и только 116 из них имеют действительно высокую мотивацию к обучению. Почти две трети кандидатов с высокими баллами ЕНТ (63,3\%) не могли демонстрировать свои способности к обучению согласно 4 критериям оценочного листа, и набрали ММИ ниже проходного балла (75\%), а также имели академические задолженности после 1 и 2 года обучения. Кандидаты с низкими баллами ЕНТ на ММИ получили соответственно низкие баллы, что свидетельствует об их низкой мотивации к обучению и низкой способности к обучению медицинским дисциплинам. Таким образом, на основе множественного мини-интервью как «входного» экзамена при поступлении в медицинские организации образования можно делать прогноз о профессиональной пригодности в будущем. Данное исследование будет проводиться до окончания студентов уровня бакалавриата, и будут анализироваться данные GPA после каждого последующего года обучения.

\section{Заключение}

Полученные нами результаты исследования позволяют сделать следующие выводы:

1. Множественное мини-интервью является эффективным методом для качественного отбора в медицинские университеты, позволяющий оценить коммуникативные, межличностные навыки и способности абитуриентов к обучению, и не требующий специальных ресурсов.

2. Множественное мини-интервью позволяет прогнозировать профессиональную пригодность у кандидатов, т.е. 23,6\% обучающихся, имеющие высокие результаты единого национального тестирования и множественного мини-интервью имеют высокие учебные достижения по результатам этапов обучения.

3. С целью качественного дифференцированного отбора в медицинские организации образования в Казахстане целесообразно официально включить в Типовые правила приема в вузы метод множественного миниинтервью как дополнительный экзамен, определяющий профессиональную пригодность к медицине.

Disclosures: There is no conflict of interest for all authors.

\section{Список литературы}

1. Akanov A.A., Khamzina N.K., Esanzhanova G.M., Akhmetov V.I. Medical Education in USA: Experience for Kazakhstan (second edition) [in Russian]. 2010; 50 p.

2. Faizullina K.M. Est' li neobkhodimost' v izmenenii pravil otbora abiturientov v medicinskii VUZi (Is there a need to change the rules for selecting applicants for medical schools) [in Russian] - Vestnik KazNMU. 2013; 1: 345-347.

3. Arulampalam W., Naylor R.A., Smith J.P. Dropping out of medical school in the UK: explaining the changes over ten years. Medical Education. 2007; 41; 385-94.

4. Stetto J.E., Gackstetter G.D., Cruess D.F., Hooper T.I. Variables associated with attrition from Uniformed Services University of the Health Sciences Medical School. Military Medicine. 2004; 169: 7-102.

5. Semenkov N.N. Socialnii problemi medicinskoi proforientacii (nauchnii obzor) (Social problems of medical career guidance (scientific review)) [in Russian]. Problema socialnoi gigieni, zdravookhraneniya i istoriya medicine. 1995; 4: 48-51.

6. Sukhareva L.M., Pavlovich K.E., Rapoport I.K., Shubochkina E.I. Professionalnaya orientaciya molodezhi: medicinskii I psykhofiziologicheskii aspect (Professional orientation of youth: medical and psycho-physiological aspects) [in Russian]. Gigiena I sanitariya. 2000; 1: 48-52.

7. Patterson F., Knight A., Dowell J., Nicholson S., Cousans F. How effective are selection methods in medical education? A systematic review. Medical Education. 2016; 50: 36-60.

8. Marc C. Marchese, Paul M. Muchinsky. The Validity of the Employment Interview: A Meta-Analysis. International Journal of Selection and Assessment. 1993; 1 (1): 18-26.

How to cite this article: Raushan Dosmagambetova, Gulshat Kemelova, Aida Kassatova, Victor Riklefs. Differentiated selection method to admission in medical education [in Russian]. J Clin Med Kaz. 2018; 2(48):41-46 